\title{
Research of toxicological safety of production and operation of products from sulfur gypsum composite
}

\author{
Yu.G. Gasan (ORCID 0000-0002-2510-4418), V.I. Tarasevich (ORCID 0000-0002-3249-7029), \\ V.B. Dolgoshey (ORCID 0000-0002-0147-3534) \\ Kyiv National University of Construction and Architecture, Povitroflotsky Avenue, 31, Kyiv, 03680, Ukraine \\ Tel.: +38044241540 \\ E-mail:vittars@ukr.net,vdolgoshey@mail.ru
}

Article info: received 07.05.2019, revised 20.05.2019, accepted 12.06.2019

Gasan, Yu.G., Tarasevich, V.I., Dolgoshey, V.B. (2019) Research of toxicological safety of production and operation of products from sulfur gypsum composite 2(43), doi: 10.26909/csl.2.2019.2

By spent researches is established, that the products from a composite material on a basis gypsum and sulfur do not include in the structure potentially dangerous for organism of the person and environment of connections of mercury, thallium, selenium, arsenic; are chemically stable and do not allocate in inducing air, water and acid of environment unstable of inorganic connections. By manufacture of products on air environment of a working zone can be allocated hydrogen sulphide and sulphureous anhydride, that requires the appropriate organization of labour of the workers with maintenance of a premise by compulsory ventilation and measures of fire-prevention safety.

Toxicological and hygienic studies of powdered sulfur gypsum material in case of cutaneous admission (50\% vaseline emulsion) allowed to establish the following: after the first application of the paste, no visible changes were observed on the skin of animals. After ten applications in $2 / 3$ of the experimental animals, pale pink erythema was observed throughout the paste application area. With further applications, the intensity of skin hyperemia did not increase. The resulting changes can be classified as a moderately pronounced skin irritating effect of powdered sulfur gypsum material.

Analysis of the information obtained during the formulation of basophil degranulation reactions and specific agglomeration of blood leukocytes of guinea pigs sensitized with powdered sulfur gypsum material indicates the absence of statistically significant changes in the parameters of the studied reactions in animals of the experimental and control groups. This gives grounds for concluding that sulfur gypsum materials do not possess allergenic activity.

Based on the conclusion of the Chief Sanitary Doctor of Ukraine, a composite material based on gypsum and sulfur is recommended for the manufacture of tiles that can be used in the construction of buildings of "B" and "V" groups (industrial and public buildings).

Key words: sulfur gypsum composite, toxicological safety.

\section{Исследование токсикологической безопасности производства и эксплуатации изделий из серогипсового композита}

\author{
Ю.Г. Гасан, В.И. Тарасевич, В.Б. Долгошей
}

Киевский национальный университет архитектуры и строительства, Киев, Украина

Проведенными исследованиями установлено, что изделия из композиционного материала на основе гипса и серы не включают в свой состав потенциально опасных для организма человека и окружающей среды соединений ртути, талия, селена, кадмия, мышьяка; являются химически стабильными и не выделяют в побуждающие воздушную, водную и кислотную среды нестабильных неорганических соединений. При производстве изделий в воздушную среду рабочей зоны могут выделяться сероводород и сернистый ангидрит, что требует соответствующей организации труда рабочих с обеспечением помещения принудительной вентиляции и мерами противопожарной безопасности. 


\section{Введение}

В последнее время в практике строительства в качестве пропиточной композиции для модифицирования капиллярно-пористых материалов, в том числе и на основе гипса, находит применение техническая сера.

Исследования проведенные в этом направлении $[1,2,3]$, показывают, что изделия из бетонов, пропитанных серой различных модификаций, могут найти широкое применение прежде всего в конструкциях и изделиях, подвергающихся в процессе эксплуатации агрессивным воздействиям, а также в конструкциях, к физико-механическим свойствам которых предъявляют повышенные требования.

\section{Материалы и методы исследования}

Для изучения вопросов, связанных с токсикологической безопасностью производства и эксплуатации серогипсовых изделий, были проведены исследования совместно с Киевским НИИ общей и коммунальной гигиены.

В задачу исследования входило решение следующих вопросов: изучение химического состава исследуемых материалов, исследование химической стабильности материалов в побуждающих воздушной и водной средах, а также при воздействии кислотных дождей; санитарно-технические исследования характеристик воздуха рабочей зоны при производстве серогипсовых изделий; токсико-гигиенические исследования серогипсовых материалов.

Основную опасность воздействия на человека и окружающую среду при изготовлении серогипсовых изделий представляют газы $\mathrm{H}_{2} \mathrm{~S}, \mathrm{SO}_{2}$, пары серы и серная пыль. По данным [1] в закрытой емкости из расплава серы при температуре $120 \ldots 150{ }^{\circ} \mathrm{C}$, в основном, будут выделяться пары серы в количестве $20 \ldots 100$ мг с 1 м² поверхности плавления. Выделение $\mathrm{H}_{2} \mathrm{~S}$ будет незначительным, т.к. его содержание в автоклавной сере и сере подземной выплавки не превышает $2 \ldots 5$ г/т, а количество десорбируемого из расплава $\mathrm{H}_{2} \mathrm{~S}$ составляет не более $5 \ldots 10 \%$ от его первоначального содержания. Пары серы при охлаждении конденсируются и превращаются в мелкодисперсную пыль. Предельно допустимая концентрация для воздуха рабочей зоны составляет $6 \mathrm{M \Gamma} / \mathrm{M}^{3}$.

При ингаляционном пути поступления пылевидной серы в концентрациях $8 \ldots 10 \mathrm{Mг} / \mathrm{M}^{3}$ в организм наблюдается снижение ферментативной активности крови, развитие гипохронной анемии, лейкоанемии. Длительное воздействие серы на слизистые оболочки и кожные покровы при концентрациях

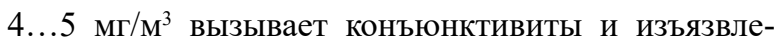
ния кожи, головокружения, общую слабость. При длительном воздействии на организм сероводород вызывает катары верхних дыхательных путей и расстройство пищеварения. Сера и сероводород не обладают эффектом отдаленных последствий для организма (концерогенным, терапогенным и эмбриотоксичным действием).

\section{Результаты и их обсуждение}

Проведенные экспериментальные исследования пропитанных расплавом серы гипсозольных образцов позволили установить, что изделия на основе технической серы Ново-Роздольского месторождения, золы - уноса Ладыженской ТЭС и гипса не включают в свой состав вредных для организма и окружающей среды соединений ртути, талия, селена, свинца, висмута и хрома. В преимущественном и количественном отношениях материал представлен серой, а также соединениями щелочных и щелочноземельных материалов (табл. 1).

Установлено, что при температуре $40{ }^{\circ} \mathrm{C}$ серогипсовые материалы не выделяют в побуждающую воздушную среду диоксида серы и сероводорода, что позволяет отнести их к химически стабильным материалам. Эксперименты показали, что в водной среде, а также в среде, имитирующей кислотные дожди, не установлены миграции неорганических соединений из исследуемых материалов.

Во время пропитки гипсозольных образцов в пропиточной камере при температуре $140 \ldots 150{ }^{\circ} \mathrm{C}$ в воздухе рабочей зоны обнаруживается серный ангидрид $\left(6,12 \mathrm{мг} / \mathrm{M}^{3}\right)$ и следовые количества се-

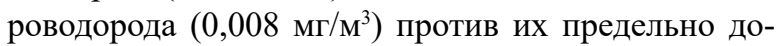
пустимых концентраций в воздухе рабочей зоны равных по $10 \mathrm{мг} / \mathrm{M}^{3}$. По количественному уровню загрязнения и качественному составу загрязнения компонентов воздушная среда производства серогипсовых изделий относится к категории «умеренно загрязненных» (III класс).

Токсиколого-гигиенические исследования порошкообразного серогипсового материала при накожном пути поступления в организм (50 \% вазелиновая эмульсия) позволили установить следующее: после первых аппликаций пасты видимых изменений на коже животных не наблюдалось. После десяти аппликаций у 2/3 экспериментальных животных наблюдалась бледно-розовая эритема по всему участку нанесения пасты. При дальнейших аппликациях интенсивность гиперемии кожи не нарастала. Полученные изменения можно классифицировать как умеренно выраженное кожнораздражающее действие порошкообразного серогипсового материала. 
ISSN 2521-6694 (Print) Ceramics: science and life, 2(43), 2019

Таблица 1.

Содержание химических элементов в серогипсовом композите

\begin{tabular}{|c|c|c|}
\hline Элементы & Концентрация, \% 10³ & Природный фон, \% 10-3 \\
\hline кремний & 3000,0 & 27000,0 \\
\hline кальций & 25000,0 & 36000,0 \\
\hline магний & 300,0 & 2100,0 \\
\hline алюминий & 80,0 & 8800,0 \\
\hline железо & 250,0 & 5100,0 \\
\hline марганец & 100,0 & 90,0 \\
\hline никель & 0,1 & 3,0 \\
\hline кобальт & 0,2 & 3,0 \\
\hline ванадий & 0,1 & 15,0 \\
\hline хром & 2,0 & 2,0 \\
\hline молибден & 0,1 & 0,3 \\
\hline вольфрам & 0 & 0,1 \\
\hline цирконий & 0,3 & 20,0 \\
\hline гафний & 0,1 & 0,3 \\
\hline ниобий & 0,1 & 2,5 \\
\hline тантал & 0 & 0,1 \\
\hline медь & 0,3 & 10,0 \\
\hline свинец & 0 & 2,0 \\
\hline серебро & 0,1 & 2,0 \\
\hline сурьма & 0 & 0,05 \\
\hline висмут & 0 & 0,03 \\
\hline цинк & 2,0 & 5,0 \\
\hline кадмий & 0 & 0,05 \\
\hline мышьяк & 0 & 0,01 \\
\hline селен & 0 & 0,01 \\
\hline таллий & 0 & 0,03 \\
\hline редкоземельные элементы (в сумме) & 0,5 & 0,5 \\
\hline литий & 6,0 & 6,5 \\
\hline натрий & 800,0 & 2640,0 \\
\hline бор & 0,1 & 0,5 \\
\hline cepa & 30000,0 & 6,0 \\
\hline
\end{tabular}

\section{Выводы}

Анализ информации, полученной при постановке реакций дегрануляции базофилов и специфической агломерации лейкоцитов крови морских свинок, сенсибилизированных порошкообразным серогипсовым материалом, указывает на отсутствие статистически достоверных изменений показателей изучаемых реакций у животных опытной и контрольной групп. Это дает основания для вывода о том, что серогипсовые материалы не обладают аллергенной активностью.

На основании заключения Главного санитарного врача Украины композиционный материал на основе гипса и серы рекомендуется для изготовления плиток, которые можно использовать при строительстве зданий групп «Б» и «В» (промышленные и общественные здания).

\section{References}

1. Орловский, Ю.И. Бетоны модифицированные серой: дис. д-ра техн. наук: 05.05.05. - Львов. - 1992. $-529 \mathrm{c}$

2. Гасан, Ю.Г., Тарасевич, В.И., Бондаренко, C.B. Специальный облицовочный строительный материал на основе гипса, модифицированного золой и серой / Будівельні матеріали, вироби та санітарна техніка. Науково-технічний збірник НДІБМВ. - Вип.15. - Київ. - 2000. - С. 87 - 89.

3. Гасан, Ю.Г., Тарасевич, В.І., Дроздова, О.В. Спеціальний облицювальний будівельний матеріал на основі гіпсу, модифікованого золою i сіркою / Міжвузівський збірник наукових праць “Наукові нотатки", Луцький національний технічний університет. - Луцьк. - 2018. - № 63. C. $56-61$. 